\title{
EHMTI-0119. Increased prevalence of migraine in patients with unruptured saccular intracranial aneurysms (SIA)
}

\author{
HD Hambardzumyan*, HM Manvelyan, GA Avagyan, HH Hakobyan, IM Gabrielyan \\ From 4th European Headache and Migraine Trust International Congress: EHMTIC 2014 \\ Copenhagen, Denmark. 18-21 September 2014
}

\section{Introduction}

Rupture of SIA causes thunderclap headache but it remains unclear whether headache in general and migraine in particular is more prevalent in patients with unruptured SIA.

\section{Aims}

In this case-control study we therefore estimate the prevalence of headaches in patients with SIA during 1 year before rupture.

\section{Methods}

Prospectively 155 consecutive patients with SIA (96 women and 59 man, mean age 45.4 years) and 184 healthy blood donors (98 men, 86 women mean age 39.6 years) received o purpose developed semistructured interview. Diagnosis were made according to the International Headache Society criteria. Aneurysms were diagnosed by conventional cerebral angiography.

\section{Results}

Headaches in patients with SIA before their diagnostics or rupture were revealed in 103 patients, therefore their 1 -year prevalence was $61.6 \%$. The mean duration of these headaches was 12.5 years, the mean age at the beginning of headaches was 30.2 years. These headaches included:migraine without aura(MO)-58(40.2\%), migraine with aura(MA)-2(1\%),tension type headache (TTH)-19(18.4\%), cluster headache $(\mathrm{CH})-2(1 \%)$, posttraumatic headaches(PH)-2(1\%).1-year prevalence of headaches in controls was $32.5 \%(58$ patients out of 184$)$, they included:TTH-41(23.2\%), MO-16(8.8\%), PH-1 $(0.5 \%)$. Among this headaches in patients with SIA and controls only the prevalence of migraine was significantly (4.5times) higher in patients with SIA (OR 4.5, 95\% CI 2.5-7.8, p 0.0001).

\section{Conclusions}

This is the first study that convincingly shows a significant association between unruptured SIA and migraine.

No conflict of interest.

Published: 18 September 2014

doi:10.1186/1129-2377-15-S1-G13

Cite this article as: Hambardzumyan et al:: EHMTI-0119. Increased

prevalence of migraine in patients with unruptured saccular intracranial aneurysms (SIA). The Journal of Headache and Pain 2014 15(Suppl 1):G13.

Neurology, Yerevan State Medical University, Yerevan, Armenia

Submit your manuscript to a SpringerOpen ${ }^{\bullet}$ journal and benefit from:

- Convenient online submission

- Rigorous peer review

- Immediate publication on acceptance

- Open access: articles freely available online

- High visibility within the field

- Retaining the copyright to your article 